\title{
Evolved Urban Form to Respond to Extreme Sea Level Events in Coastal Cities
}

\author{
Wang Liangling ${ }^{1,2}$ and Han Jie ${ }^{1}$ \\ 1. School of Architecture and Civil Engineering, Xiamen University, Xiamen 361005, China \\ 2. School of Design and Environment, National University of Singapore, 119077, Singapore
}

\begin{abstract}
Along with climate change and global warming, ESLEs (extreme sea level events) are seriously threatening coastal cities' development. In order to respond to such events, transformational adaptation strategy in urban planning might play an important role. For instance, it has been proposed that BCR (building coverage ratio) should be minimized to a certain range in order to enhance coastal areas' resiliency. For the purpose of urban planning practices, the main objective of this research is to develop a method which could formulate the proper BCR range in vulnerable coastal areas. The research is conducted through simulating storm surge floods in simplified waterfront settlements with different BCRs. Data representing the impact of ESLEs collected through CFD (computational fluid dynamic) simulations has been examined. This research has proved that in dense coastal areas, ESLEs may cause serious damage to the built environment if their protective structures fail. It showed that controlling BCR is an effective way to enhance their resiliency. When the BCR is low, the pressure caused by storm surge floods and wave height can be greatly reduced. However, decreased BCR may also reduce land utilization efficiency. Simulation results indicated that controlling the BCR to around $36 \%$ might be the most effective scenario which balances resiliency and land use efficiency. They also showed that under the same storm surge flood scenario, the pressures caused by flood waves could be reduced if the length of the building is increased. This study might be considered as transformational adaptation measures that contributes some knowledge for waterfront development in vulnerable locations, and it also provides scientific and useful proof for sustainable strategies in coastal cities and reveals that particular urban design tools, such as BCR control, could play an essential role in responding to ESLEs.
\end{abstract}

Key words: ESLEs, BCR, transformational adaptation, CFD simulation.

\section{Introduction}

In human history, coastal cites prospered due to their favorable locations with navigable water and defensive harbors [1]. Nowadays, these cities still play highly important roles in shaping the global economy. Nevertheless, environmental issues and global warming have raised great challenges to their developments. In other words, most of them have to bear the brunt of climate change impacts, including land subsidence, violent storms and extreme sea level variations.

Although the main reasons for global warming remain debatable, human beings have suffered from their consequences, of which extreme sea level events might be one of the severest, affecting billions of

Corresponding author: Han Jie, Ph.D., assistant professor, research field: urban design. people. For instance, the 2004 Indian Ocean tsunami killed over 230,000 people in inundated coastal settlements in 14 countries [2]. Additionally, in March 2011, powerful tsunami waves triggered by a 9 magnitude earthquake reached heights of up to $40.5 \mathrm{~m}$ on coastal areas of Miyako in Tōhoku's Iwate Prefecture, Japan [3], which caused tremendous fatalities, injuries and damages, resulting in huge economic losses. In the warmer future, more human settlements might be affected in more drastic ways as Pachauri [4] has predicted that sea storms may continue to increase in terms of intensity and frequency. Nicholls and Mimura's study [5] has shown that by the year of 2100, 600 million people will inhabit coastal floodplains (below the 1 in 1,000-year storm surge). For this reason, to understand how the rising sea levels and changing climates affect coastal cities, and more 
importantly, to propose effective response measures to city planners may become quite urgent tasks for urban research.

\section{Sea Level Rise and Extreme Sea Level Event}

According to IPCC (Intergovernmental Panel on Climate Change) [6], oceans' thermal expansion is the most essential reason for global mean SLR (sea level rise) and has contributed around a 57\% increase since 1993. Due to its slow reaction to temperature change, sea water will expand in this century even if global warming could be stopped immediately, which means that it might be impossible to stop SLR in the near future. Based on the Climate Change 2007, the Fourth Assessment Report (AR4) of IPCC [6], it is projected that mean SLR at the end of this century may reach $60 \mathrm{~mm}$. Although it is the most often quoted data so far, IPCC's estimation has been criticized as being too optimistic. Some researchers assert that SLR could reach more than $1 \mathrm{~m}$ by the end of this century [7].

Although future uncertainties exist, SLR has resulted in serious impacts on coastal areas. The direct threats caused by the rising sea are coastal land loss and subsidence. For instance, some Pacific island nations, such as Tuvalu are already on the verge of being submerged. In Asia, many densely built coastal cities with relatively large population, such as Hong Kong, Singapore, Tianjin, Tokyo and Shanghai are suffering land subsidence at a rapid rate [8-10].

In addition, increasing risks from ESLEs (extreme sea level events), including storm surge flood, tsunami, etc. are also threatening the development of coastal cities. It is not difficult to understand that SLR could weaken the capacity of defensive structures by increasing tidal levels. Although it is not a consensus that some climate systems (characteristics of ENSO (El Nino Southern Oscillation), large-scale atmospheric circulation) will change their behaviors along with global warming, the alterations to sea surface temperatures could be one of the important factors which change the frequency and intensity of tropical cyclones [11]. IPCC [6] has projected an increase of $10 \% \sim 20 \%$ in tropical cyclone intensity if the sea surface temperatures increase by $2 \sim 4{ }^{\circ} \mathrm{C}$ from the current temperature. Meanwhile, another research [12] has addressed the issue that if the mean sea level rises with all other conditions being the same, present ELSEs will be attained more frequently, which means that the increase in maximum heights will equal to the increase in mean sea level. Accordingly, even a small increase in sea levels would have severely negative effects on low-lying islands [13]. The Pacific oceans will especially face the largest relative increase in flood risk [14]. In addition, Walsh and Betts [15] predicted that rising seas may increase the incidence of coastal flooding, either by increasing the height of storm surges, or by acting as a higher seaward barrier which restricts the escape of flood waters.

\section{Response Mechanisms to Cope with Climate Change}

Based on the above discussion, serious damages seem inevitable if coastal cities take no actions. Generally, response mechanisms to cope with climate change events cloud be categorized into two main sections, namely mitigation and adaptation [16]. Compared to adaptations, most countries and organizations focus more on the mitigation measures as it has been advised that mitigation should have priority [17]. Biesbroek et al. [18] argued that for the last two decades, climate policies in European countries have focused almost exclusively on mitigation. Nevertheless, to respond to SLR and related extreme events, mitigation strategies may not be effective since SLR might not be stopped or slowed down in the next several decades. After the turn of the century, with increasing impacts of climate change being observed including several fierce coastal disasters, adaptation has been emphasized in policy agendas [18]. According to Huq et al. [19], adaptation to climate change might be more important than 
mitigation, especially for vulnerable cities.

According to IPCC, adaptation to climate change refers to "the adjustment in natural or human systems in response to actual or expected climates and weather, or their effects, in order to moderate harm or exploit beneficial opportunities" [20]. The idea of adaptability in architecture and urbanism has been developed to be a capacity to adapt to the changing circumstances, including socio-cultural, economic and environmental changes. Ruskeepää [21] argued that climate change has become the most prominent impetus for a re-thinking of adaptation in urbanism, as it seeks to develop the best way to modify cites in order to cope with the expected changes based on the projected possible impacts [22].

\section{Adaptation to Respond to ESLEs}

Regarding SLR and ESLEs, Dronkers and Gilbert [23] label adaptation measures by three main approaches, including retreat, protection and accommodation. Retreat means abandonment of land and structures in vulnerable areas and resettlement of inhabitants [23]. However, for dense coastal cities with large population, such as Singapore and Hong Kong, retreat is not an acceptable option as there would be little land for resettlements, not to mention the degradation of economy caused by the decrease of market land [24].

Protection strategy involves defensive measures and activities to protect areas against inundation, tidal flooding, effects of waves on infrastructures, shore erosion, salinity intrusion, and the loss of natural resources [23]. Nowadays, protection is the highly recommended strategy and has been implemented in the majority of low-lying coastal areas. It has been demonstrated that protection measures are effective to cope with land loss and water intrusion. Nonetheless, based on the observations of past events, protections may not be sufficient to withstand fierce sea level variations. Accordingly, in order to mitigate the damage from ELSEs, accommodation should also be considered necessary.

Accommodation means taking measures on buildings and other built environments in order to keep them running normally under the circumstance of SLR, and it requires advanced planning [23]. Currently, in this category, the majority of research attentions have been given to building sectors, such as the enhancement of building codes and of construction regulations $[17,25]$. Case studies on a larger scale, including using projected SLR for master planning and land use planning, and evacuation route planning could be found in literatures. However, a research gap may exist on the meso-scale.

\section{Transformational Adaptation for Waterfront Development}

Kates [26] further divided adaptation measures into two sub-categories, namely transformational adaptation and incremental adaptation. According to their theory, incremental adaptation to climate change refers to "extensions of actions and behaviors that already reduce the losses or enhance the benefits of natural variations in climate and extreme events"; On the other hand, three classes of adaptations could be described as transformational adaptations, including "those that are adopted at a much larger scale or intensity; those that are truly new to a particular region or resource system; and those that transform places and shift locations" [26]. They also stated that, currently, the majority of the planned or implemented climate change adaptations could be classed as incremental measures. However, as Schiffman [27] stated, past experience of handling climate variations might not be adequate for future climate change events. Hence, the severe climate change in future years might become the incentives for governments and research groups to devote more efforts and resources in order to develop innovative adaptations, which may arm vulnerable locations and enhance their resiliency.

From the introduction of adaptation to ESLEs, most measures could be considered as incremental 
adaptation. The absence of transformational adaptation, especially the limited understanding about spatial planning measures to enhance waterfront resiliency, could result in increasing damages as the observed impacts of climate change increase in terms of frequency and intensity. Although a few researchers advocate that urban spatial layouts of waterfront in coastal cities might play an important role, in-depth studies in this area are scarcely found. ESLEs in this era are more serious than any other periods in human history and have driven us to change the way to build our coastal cities. However, currently, the research on creative adaptations to ESLEs is not sufficient yet. Therefore, this research aims to regard controlling the building coverage ratio as a pilot study to promote transformational adaptation to ESLEs.

\section{Building Coverage Ratio Control}

In the limited literature regarding this topic, it is hypothetically proposed that controlling the building coverage ratio might be useful to reduce the potential damage caused by ESLEs. BCR (building coverage ratio), also known as coverage ratio, building coverage, building footprint and lot coverage, refers to the ratio between the ground floor area of the building or buildings and the lot area. It is an essential parameter to control urban density and development intensity for local planning departments.

Bush et al. [25] emphasized the importance to restrict the BCR in coastal areas. Similarly, Davoudi et al. [17] also advocated that the development density should be rigorously restricted in coastal areas because in dense and compact urban areas, narrow streets may flood more easily, and runoff drainage may be retarded, possibly resulting in deep flooding. Based on the observations of the 2011 Japanese Tsunami, the National Geographic Channel released a documentary-Japan's Tsunami: How It Happened [28]. It shows that when the tsunami invaded some coastal towns, the wave height increased dramatically due to narrow streets and high coverage ratio.
Based on above discussions, BCR should be minimized to a certain range in order to reduce the damage caused by ESLEs. However, this issue is complicated by the high market value of the coastal land. In most cases, urban planners are confronted with the dilemma to balance coastal resiliency and land utilization efficiency.

Therefore, for the purpose of waterfront development practices, the main objective of this research is to develop a method for urban planners to formulate the proper BCR in vulnerable coastal areas. The research is conducted through simulating the storm surge wave activities in several layouts with different BCRs. During the simulations, data was collected, including the pressures endured by the buildings and the wave heights on the streets. The specific research method is elaborated in the next section.

\section{Method}

This research employed CFD (computational fluid dynamic) simulation, which is an effective tool to analyze questions involving fluid flow. The software "scSTREAM" was used to perform the required calculations to simulate the interactions of liquids or gases with surfaces defined by boundary conditions [29]. Two case studies were carried out in this research. Case Study 1 was intended to reveal the optimum BCR value for coastal areas, in which simplified grid urban layouts with typical BCRs were designed for comparison. The construction lot was designed as a $1,000-\mathrm{m}^{2}(125 \mathrm{~m} \times$ $80 \mathrm{~m}$ ) rectangle. In order to facilitate the comparison and analysis, building unit is identically designed as a cube $\left(20 \times 20 \times 20 \mathrm{~m}^{3}\right)$, which might represent the scale of small individual houses. Through different combinations (Models A, B, C, D, E and F) of the building units, the BCRs in the same lot are respectively $16 \%, 24 \%, 36 \%, 48 \%, 60 \%$ and $80 \%$ as shown in the Table 1 . These samples covered most of the typical BCR values in real urban developments.

Case Study 2 was inspired by the results of Case Study 1. Its objective was to check the effect of 
increasing the length of buildings. As shown in Fig. 1, two models were designed for this case, namely
Model G and Model H. The Model G is composed of 16 smaller units (width $=35 \mathrm{~m}$, length $=60 \mathrm{~m}$,

Table 1 Models for Case 1 (Models A, B, C, D, E and F).

\begin{tabular}{|c|c|c|c|}
\hline Model & Number of units & $\mathrm{BCR}(\%)$ & Layout \\
\hline Model A & 4 & 16 & \\
\hline Model B & 6 & 24 & \\
\hline Model C & 9 & 36 & \\
\hline Model D & 12 & 48 & \\
\hline Model E & 15 & 60 & \\
\hline Model F & 20 & 80 & \\
\hline
\end{tabular}

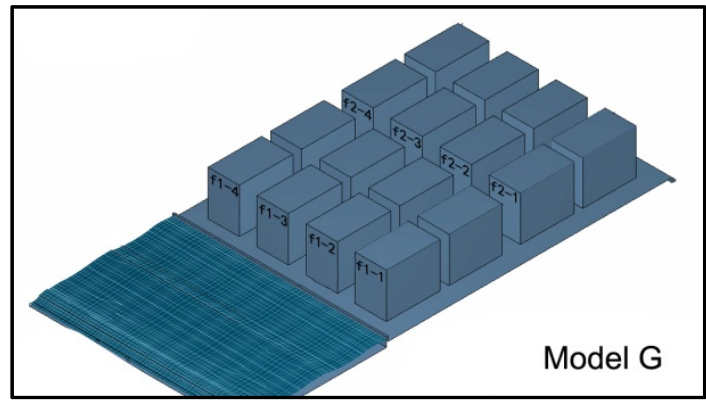

(a)

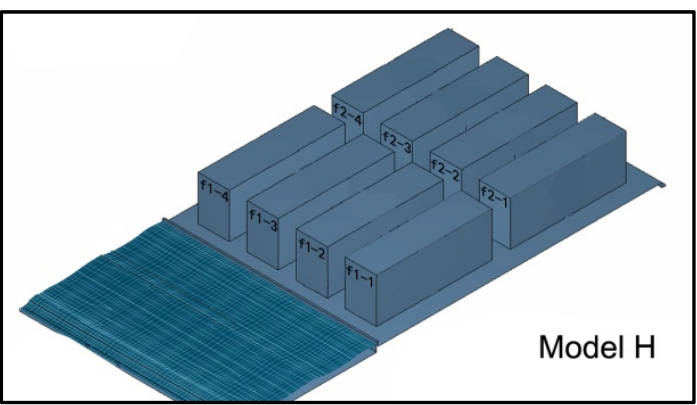

(b)

Fig. 1 Models for Case 2: (a) Models G; (b) Model H. 


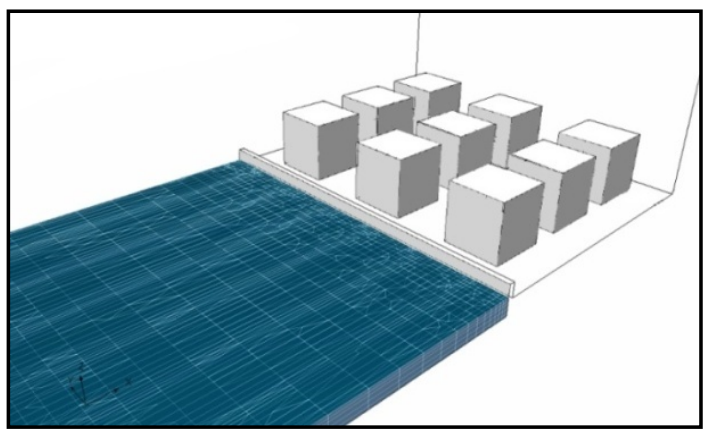

Fig. 2 Urban setting for simulations.

height $=50 \mathrm{~m}$ ), while the Model $\mathrm{H}$ is composed of 8 relatively bigger units (width $=35 \mathrm{~m}$, length $=130 \mathrm{~m}$, height $=50 \mathrm{~m}$ ). The size of units in could represent the bottom parts of commercial and public buildings in downtown areas. The BCRs of these two models are slightly different ( $44 \%$ in $\mathrm{G}$ and $47 \%$ in $\mathrm{H}$ ).

The same research method was applied in Cases 1 and 2, and the four steps are:

(1) The first step was to build digital models based on the combinations discussed above and to apply the models to a simplified urban coastal environment, which was equipped with a seawall to protect the waterfront from a relatively high sea level (Fig. 2);

(2) In the second step, a severe storm surge with the wave height of $5 \mathrm{~m}$ and the wave period of $10 \mathrm{~s}$ was simulated by CFD software. The storm surge was designed to break the protection of the seawall and run into the coastal area;

(3) In the third step, the pressures endured by the buildings and the wave heights on the streets were recorded during the simulations. Before this, all the facades facing the sea were registered in simulations, and several points adjacent to the buildings were identified;

(4) In the final step, the collected data including pressures and wave heights were analyzed and compared in order to understand the diverse wave activities in special urban layouts with different BCRs or building sizes.

\section{Results of Case Study 1}

The results of pressures in Case 1 are summed up in Table 2. As the total number of building units varies, the pressures were compared based on their relative locations. The maximum and average values of the recorded pressures in the first row, second row and third row were compared, respectively.

As shown in Table 1, the average pressure on the facades increases with the BCR ranging from $16 \%$ to $60 \%$. From $16 \%$ to $36 \%$, the growth rate of the average pressures on the first row is around $10,000 \mathrm{~N}(2 \%)$. However, it changes quite dramatically after BCR exceeds $36 \%$. Compared to Model C $(\mathrm{BCR}=36 \%)$, the average pressure on the first row in Model $\mathrm{D}$ $(\mathrm{BCA}=48 \%)$ increases by $12.8 \%$, from $545,178 \mathrm{~N}$ to $615,769 \mathrm{~N}$. When the BCR increases to $60 \%$ (Model E), the average pressure on the first row increases to $726,558 \mathrm{~N}$, which is $117 \%$ of Model D and $133 \%$ of Model C. Similarly, in the second and third rows, the average pressures on the facades increase with the same tendency.

Table 2 Pressures on the façades.

\begin{tabular}{|l|l|l|l|l|l|l|l|}
\hline Model & A & B & C & D & E & F \\
\hline Build coverage ratio (\%) & 16 & 24 & 36 & 48 & 60 & 80 \\
\hline $\begin{array}{l}\text { Max pressure on the first } \\
\text { row }\end{array}$ & Building number & $1-2$ & $1-3$ & $1-3$ & $1-4$ & $1-5$ & 5 \\
\cline { 2 - 8 } & Value (N) & $1,550,000$ & $1,990,000$ & $1,930,000$ & $2,430,000$ & $3,522,860$ & $2,710,000$ \\
\hline Average pressure on the first row & $522,194.9$ & $532,185.7$ & 545,178 & $615,769.3$ & $7,265,58.4$ & 614,000 \\
\hline $\begin{array}{l}\text { Max pressure on the } \\
\text { second row }\end{array}$ & Building number & $2-2$ & $2-3$ & $2-3$ & $2-4$ & $2-5$ & N/A \\
\cline { 2 - 8 } & Value & 796,553 & 775,628 & 676,908 & 925,139 & $1,110,440$ & N/A \\
\hline $\begin{array}{l}\text { Average pressure on the second row } \\
\text { Max pressure on the }\end{array}$ & Building number & N/A & N/A & $2-3$ & $3-4$ & $3-5$ & N/A \\
\cline { 2 - 8 } \\
third row & Value & N/A & N/A & 527,926 & 634,808 & 696,775 & N/A \\
\hline Average pressure on the third row & N/A & N/A & $419,301.6$ & $423,229.3$ & $427,262.2$ & N/A \\
\hline
\end{tabular}


The maximum pressure on the facades is more complicated than the average values as is shown in the Table 2. Compared to Model B, the maximum pressure in Model $\mathrm{C}$ decreases slightly although the building units increase. For Models C and D, the values of maximum pressure in the first row and second row increase dramatically. This result indicates that Model $\mathrm{C}$ with $\mathrm{BCR}=36 \%$ might be the best scenario to balance coastal resiliency and land utilization ratio. Obviously, its land utilization ratio is higher than that of Models A and B. Moreover, its capacity to deal with extreme sea level events is much better than that of Models D and E, and even slightly better than the case of Model B.

Interestingly, the simulation results show that both the average pressure and maximum pressure recorded for Model F are less than the values for Model E. For example, the average pressure decreases from $726,558 \mathrm{~N}$ to $614,000 \mathrm{~N}$, and it is even lower than the average pressure in Model D. One possible explanation for this might be the difference of the streets pattern as in Model F, there are only streets perpendicular to the coastal line.
Besides the pressures on the surface of buildings, the wave height on the streets is also an important parameter to assess the damage caused by extreme sea level events. In this research, several points near the buildings were selected to record wave heights. The results are shown in Table 3.

During the simulation, a storm surge which lasted around $150 \mathrm{~s}$ was created. The wave broke over the dam at the 30th second and reached buildings at different times. Generally, the wave heights decreased over time in all cases.

As the peak value of a wave height is the most important parameter to measure the wave height and also an essential factor to evaluate how serious the storm surge is, this research collected peak values to compare the wave heights. As it is shown in Table 3, in the first row, the highest wave level appears in Model E, which is $4.17 \mathrm{~m}$ above the ground. Hence, the lower value shows in Model $\mathrm{C}$, which is $2.97 \mathrm{~m}$ above ground. This result indicates again that Model C $(\mathrm{BCR}=36 \%)$ might be the most effective layout to mitigate the damage caused by extreme sea level events.

In the second row, the peak values of waves increase

Table 3 Maximum wave height on the streets.

\begin{tabular}{|c|c|c|c|c|c|}
\hline Model & $\mathrm{BCR}(\%)$ & Row number & Building number & Time $(\mathrm{s})$ & Max wave height occurred on the streets (m) \\
\hline \multirow{2}{*}{ A } & \multirow{2}{*}{16} & Row 1 & $1-2$ & 151 & 3.52 \\
\hline & & Row 2 & $2-1$ & 126 & 1.96 \\
\hline \multirow{2}{*}{ B } & \multirow{2}{*}{24} & Row 1 & $1-3$ & 151 & 3.20 \\
\hline & & Row 2 & $2-2$ & 136 & 1.73 \\
\hline \multirow{3}{*}{$\mathrm{C}$} & \multirow{3}{*}{36} & Row 1 & $1-2$ & 118 & 2.97 \\
\hline & & Row 2 & $2-3$ & 143 & 2.05 \\
\hline & & Row 3 & $3-3$ & 125 & 1.84 \\
\hline \multirow{3}{*}{$\mathrm{D}$} & \multirow{3}{*}{48} & Row 1 & $1-3$ & 148 & 4.09 \\
\hline & & Row 2 & $2-4$ & 144 & 2.56 \\
\hline & & Row 3 & $3-4$ & 148 & 1.95 \\
\hline \multirow{3}{*}{$\mathrm{E}$} & \multirow{3}{*}{60} & Row 1 & $1-4$ & 149 & 4.80 \\
\hline & & Row 2 & $2-5$ & 143 & 2.86 \\
\hline & & Row 3 & $3-3$ & 145 & 1.90 \\
\hline \multirow{4}{*}{$\mathrm{F}$} & \multirow{4}{*}{80} & Row 1 & $1-3$ & 137 & 4.17 \\
\hline & & Row 2 & $2-5$ & 132 & 3.00 \\
\hline & & Row 3 & $3-5$ & 134 & 2.90 \\
\hline & & Row 4 & $4-5$ & 137 & 2.65 \\
\hline
\end{tabular}

Note: because the ground height is $5 \mathrm{~m}$, the max value of wave height shown in this table should subtract $5 \mathrm{~m}$. 
Table 4 Results of Case Study 2.

\begin{tabular}{|c|c|c|c|c|c|c|c|c|}
\hline \multicolumn{9}{|c|}{ Model G: width $=35 \mathrm{~m}$, length $=60 \mathrm{~m}$, height $=50 \mathrm{~m}$} \\
\hline Building number & f1-1 & f1-2 & f1-3 & f1-4 & $\mathrm{f} 2-1$ & $\mathrm{f} 2-2$ & $\mathrm{f} 2-3$ & $\mathrm{f} 2-4$ \\
\hline Maximum pressure & $5.00 \mathrm{E}+06$ & $5.30 \mathrm{E}+06$ & $5.98 \mathrm{E}+06$ & $5.73 \mathrm{E}+06$ & $1.67 \mathrm{E}+06$ & $1.76 \mathrm{E}+06$ & $1.59 \mathrm{E}+06$ & $1.60 \mathrm{E}+06$ \\
\hline Average pressure & $2.24 \mathrm{E}+06$ & $2.28 \mathrm{E}+06$ & $2.04 \mathrm{E}+06$ & $2.13 \mathrm{E}+06$ & $2.13 \mathrm{E}+06$ & $1.49 \mathrm{E}+06$ & $1.48 \mathrm{E}+06$ & $1.48 \mathrm{E}+06$ \\
\hline \multicolumn{9}{|c|}{ Model H: width $=35 \mathrm{~m}$, length $=130 \mathrm{~m}$, height $=50 \mathrm{~m}$} \\
\hline Building number & f1-1 & f1-2 & f1-3 & f1-4 & $\mathrm{f} 2-1$ & $\mathrm{f} 2-2$ & f2-3 & f2-4 \\
\hline Maximum pressure & $4.32 \mathrm{E}+06$ & $5.41 \mathrm{E}+06$ & $5.38 \mathrm{E}+06$ & $5.54 \mathrm{E}+06$ & $1.86 \mathrm{E}+06$ & $1.73 \mathrm{E}+06$ & $1.60 \mathrm{E}+06$ & $1.62 \mathrm{E}+06$ \\
\hline Average pressure & $2.25 \mathrm{E}+06$ & $2.18 \mathrm{E}+06$ & $2.01 \mathrm{E}+06$ & $2.06 \mathrm{E}+06$ & $1.49 \mathrm{E}+06$ & $1.49 \mathrm{E}+06$ & $1.48 \mathrm{E}+06$ & $1.48 \mathrm{E}+06$ \\
\hline
\end{tabular}

gradually from Model B to Model F. In the third row, these peak values in Models C, D and E are almost the same. In Model F, from the first row to the last row, the wave height remains relatively high as expected, decreasing from $4.17 \mathrm{~m}$ in the first row to $2.65 \mathrm{~m}$ in the fourth row.

\section{Results of Case Study 2}

From the comparison between Models $\mathrm{E}$ and $\mathrm{F}$ in the first case study, it was shown that changing the layout of waterfronts from pavilions to strips might be helpful to reduce the pressure on the facades. Therefore, in the second case study, Models $\mathrm{G}$ and $\mathrm{H}$ were created to carry out a future test. Different from Case 1, except for maximum pressure, the total pressures (accumulated value of 8,000 samples in almost $200 \mathrm{~s}$ ) on each facade in Case 2 were also calculated. Results of Case 2 are summed up in Table 4. Basically, it proves the results of Case 1. As shown in Table 4, in the first row, expect f1-2, the maximum pressures record for Model $\mathrm{H}$ is lower than those for Model G. On f1-1, it reduces by $13.6 \%$ (from 5.00E $+06 \mathrm{~N}$ in Model $\mathrm{G}$ to $4.32 \mathrm{E}+06 \mathrm{~N}$ in Model $\mathrm{H}$ ); on $\mathrm{fl}-3$, it reduces by $10 \%$ (from $5.98 \mathrm{E}+06 \mathrm{~N}$ in Model $\mathrm{G}$ to $5.38 \mathrm{E}+06 \mathrm{~N}$ in Model H); And on $\mathrm{fl}-4$, it reduces by $3 \%$ (from $5.73 \mathrm{E}+06 \mathrm{~N}$ in Model $\mathrm{G}$ to $5.54 \mathrm{E}+06 \mathrm{~N}$ in Model $\mathrm{H}$ ). The result of maximum pressure on $\mathrm{fl-2}$ is an exception as it decreases $2 \%$ (from $5.30 \mathrm{E}+06 \mathrm{~N}$ in model $\mathrm{G}$ to $5.41 \mathrm{E}+06 \mathrm{~N}$ for Model $\mathrm{H}$ ). In terms of total pressures, all values for Model $\mathrm{G}$ are slightly higher than those for Model H except on f1-1.

The comparison between the third row of Model G and the second row of Model $\mathrm{H}$ shows that the difference between the two models is not as much as that is in the first row. The maximum pressures on $\mathrm{f} 2-2$, f2-3 and f2-4 decrease slightly for Models $G$ and $H$, while the one on $\mathrm{f} 2-1$ shows a relatively larger increase (11.4\%, from 1.67E $+06 \mathrm{~N}$ for Model $\mathrm{G}$ to $1.86 \mathrm{E}+06 \mathrm{~N}$ for Model $\mathrm{H}$ ). No variation is found in the total pressures between the two models.

\section{Conclusions}

It is usual that urban planners would reduce BCR in vulnerable coastal areas in order to improve resiliency. Case Study 1 indicates that the pressures on buildings and the wave heights are not exactly proportional to the $\mathrm{BCR}$. By considering the land utilization ratio and the capacity to mitigate the damage caused by ESLEs, the research reveals that Model $\mathrm{C}$ whose $\mathrm{BCR}$ is around $36 \%$, seems to be the best choice to carry out the developments of coastal areas.

This research proves that in dense coastal areas, ESLEs may cause serious damage to urban environments if the protective structures fail. In addition, controlling the building coverage ratio is an effective way to enhance the resiliency of coastal areas. When the BCR is low, the pressure caused by storm surge floods and wave height can be highly reduced. However, decreasing BCR may reduce the land utilization efficiency, which might not be acceptable for some coastal cities with a shortage of land. The first case study indicates that there might be an optimum range to balance resiliency and land use efficiency. Besides, it also indicates that under same storm surge flood scenario, the pressures caused by flood waves could be reduced if the length of the building is 
increased. Although the results of this study need future tests, it is assumed that the decrease of pressures might be caused by the difference in water level between the front and rear sides of the structures.

The result of this study may be considered as transformational adaptation measures, which contributes some knowledge to waterfront development in vulnerable locations, and which also provides scientific and useful proofs for sustainable strategies in coastal cities and reveals that particular urban design tools, such as BCR control as discussed in this research, could play an essential role to respond to ESLEs. For new development schemes around coastlines or on reclaimed land, the method employed in the research could become an instructive assessment methodology for urban planning departments to identify the optimum BCR range.

As this research is still in a preliminary stage, some factors were simplified in simulations, including building shapes and street patterns. These factors may influence the results. Therefore, in future, more simulations should be carried out based on real urban built environments. The results could be more convincing if they could be applied in certain coastal cities.

For centuries, urbanists like Ebenezer Howard [30], Le Corbusier [31] and Frank Lloyd Wright [32] have been trying to propose perfect urban models, including the garden city, the broadacre city and the radiant city. All efforts were focused on social and environmental issues of their own times. In our era, the challenge from climate change is more challenging than ever before. As contemporary urban researchers, our responsibility shifts to develop urban models which are adaptive to climate change, and the fundamental criterion for these models is sustainability. Although this preliminary research is far away from proposing perfect models for waterfronts, it indicates that spatial arrangement tools and designing specific urban fabric may enhance the resiliency of waterfronts. It could be considered as the initiative to develop transformational adaptations and sustainable models for coastal cities which are struggling with the rising sea.

\section{Acknowledgments}

This research is founded by World Future Foundation.

\section{References}

[1] Wrenn, D. M., Casazza, J., and Smart, E. 1983. Urban Waterfront Development. Washington, D.C: Urban Land Institute.

[2] Paris, R., Lavigne, F., Wassmerc, P., and Sartohadid, J. 2007. "Coastal Sedimentation Associated with the December 26, 2004 Tsunami in Lhok Nga, West Banda Aceh (Sumatra, Indonesia)." Marine Geology 238 (1-4): 93-106.

[3] Yalciner, A. C., Ozer, C., Zaytsev, A., Suppasri, A., Mas, E., and Kalligeris, N., et al. 2011. "Field Survey on the Coastal Impacts of March 11, 2011 Great East Japan Tsunami." In Proccedings of 2011 WCCE-ECCE-TCCE Joint Conference on Seismic Protection of Cultural Heritage, 123-40.

[4] Pachauri, R. K. 2008. Climate Change 2007. Synthesis report, contribution of Working Groups I, II and III to the fourth assessment report.

[5] Nicholls, R., and Mimura, N. 1998. "Regional Issues Raised by Sea-Level Rise and Their Policy Implications." Climate Research 11: 5-18.

[6] IPCC (Intergovernmental Panel on Climate Change). 2007. Climate Change 2007. Synthesis report summary for policymakers.

[7] Rahmstorf, S. 2007. "A Semi-empirical Approach to Projecting Future Sea-Level Rise.” Science 315 (5810): 368-70.

[8] Chai, J., Shen, S. L., Zhu, H. H., and Zhang, X. L. 2004. "Land Subsidence Due to Groundwater Drawdown in Shanghai." Geotechnique 54 (2): 143-7.

[9] Hu, R., Yue, Z. Q., Wang, L. C., and Wang, S. J. 2004. "Review on Current Status and Challenging Issues of Land Subsidence in China." Engineering Geology 76 (1): 65-77.

[10] Phien-Wej, N., Giao, P., and Nutalaya, P. 2006. "Land Subsidence in Bangkok, Thailand." Engineering Geology 82 (4): 187-201.

[11] Walsh, K., and Pittock, A. 1998. "Potential Changes in Tropical Storms, Hurricanes, and Extreme Rainfall Events as a Result of Climate Change." Climatic Change 39 (2): 199-213.

[12] Nurse, L. A., Sem, G., Hay, J. E., Suarez, A. G., Wong, P. P., and Briguglio, L. 2001. Small Island States. New York: 
Cambridge University Press.

[13] Forbes, D., and Solomon, S. 1997. “Approaches to Vulnerability Assessment on Pacific Island Coasts: Examples from Southeast Viti Levu (Fiji) and South Tarawa (Kiribati)." Presented at 3rd SPREP Meeting on Climate Change and Sea-Level Rise in the Pacific, Noumea, New Caledonia.

[14] Field, C. B., Barros, V., and Stocker, T. F. 2012. "Managing the Risks of Extreme Events Disasters to Advance Climate Change Adaptation." Recherche 67: 02.

[15] Walsh, K. J. E., Betts, H., Church, J., Pittock, A. B., McInnes, K. L., and Jackett, D. R., et al. 2004. "Using Sea Level Rise Projections for Urban Planning in Australia." Journal of Coastal Research 20 (2): 586-98.

[16] Sharma, D., and Tomar, S. 2010. "Mainstreaming Climate Change Adaptation in Indian Cities." Environment and Urbanization 22 (2): 451-65.

[17] Davoudi, S., Crawford, J., and Mehmood, A. 2009. Planning for Climate Change : Strategies for Mitigation and Adaptation for Spatial Planners. London: Earthscan.

[18] Biesbroek, G. R., Swart, R. J., Timothy, R. C., Cowan, C., Henrichs, T., and Mela, H., et al. 2010. "Europe Adapts to Climate Change: Comparing National Adaptation Strategies." Global Environmental Change 20 (3): 440-50.

[19] Huq, S., Kovats, S., Reid, H., and Satterthwaite, D. 2007. "Editorial: Reducing Risks to Cities from Disasters and Climate Change." Environment and Urbanization 19 (1): 3-15.

[20] Parry, M. L. 2007. Climate Change 2007: Impacts, Adaptation and Vulnerability: Working Group II Contribution to the Fourth Assessment Report of the IPCC Intergovernmental Panel on Climate Change. Cambridge: Cambridge University Press.
[21] Ruskeepää, L. A. D. 2011. "Adaptation and Adaptability: Expectant Design for Resilience in Coastal Urbanity." M.Sc. thesis, Massachusetts Institute of Technology.

[22] Cohen, N. 2011. Green Cities: An A-to-Z Guide. California: SAGE.

[23] Dronkers, J., Gilbert, J. E., Butler, L. W., Carey, J. J., Campbell, J., and James, E., et al. 1990. Strategies for Adaptation to Sea Level Rise. Report of the IPCC (Intergovernmental Panel on Climate Change) Coastal Zone Management Subgroup.

[24] Ng, W. S., and Mendelsohn, R. 2006. "The Economic Impact of Sea-Level Rise on Nonmarket Lands in Singapore." Ambio 35 (6): 289-96.

[25] Bush, D. M., Pilkey, O. H., and Neal, W. J. 1996. Living by the Rules of the Sea. Durham, N.C.: Duke University Press.

[26] Kates, R. W., Travis, W. R., and Wilbanks, T. J. 2012. "Transformational Adaptation When Incremental Adaptations to Climate Change are Insufficient." Proceedings of the National Academy of Sciences 109 (19): 7156-61.

[27] Schiffman, H. S. 2011. Green Issues and Debates: An A-to-Z Guide. California: SAGE.

[28] Kern, S., and Ludgate, S. 2011. Japan's Tsunami: How It Happened. London: Channel 4.

[29] Anderson, J. D., and Wendt, J. F. 1995. Computational Fluid Dynamics. New York: McGraw-Hill.

[30] Howard, E. 1965. Garden Cities of To-morrow. Cambridge, Massachusetts: MIT Press.

[31] Corbusier, L. 1987. The City of To-morrow and Its Planning. Mineola, New York: Courier Dover Publications.

[32] Wright, F. L. 1932. The Disappearing City. New York: W.F. Payson. 